\title{
Variações de Paz sobre um Tema de Guerra (OPUS I)
}

\section{CORSINDIO MONTEIRO DA SILVA}

\section{Assistente Jurídico do DASP}

cion 1 - Freqüentes vezes se lê ou se ouve que determinado fun. de aario pediu demissão do cargo. Ora, demissão não é sinônimo exoneração ou dispensa. Demissão é pena disciplinar, em termos estatutários. Na linguagem trabalhista, sim (art. 500 da ConSolidação das Leis do Trabalho), se usa dizer pedido de demissão do empregado estável.

$d_{e} 2$ - Reintegração, reversão e aproveitamento são formas do reingresso no serviço público. Reintegração refere-se a demiticionáriorsão, a funcionário aposentado. Aproveitamento, a fun. cionário disponivel.

ment Certo autor brasileiro, em livro de larga aceitação, recentepúbte editado, ensina: "Reintegração é o reingresso no serviço ressar, decorrente de decisão judicial passada em julgado, com Var dicial". a reintegração é sempre em decorrência de mandado ju-

A lição é pouca e ainda pouco clara.

sarc Reintegração é o reingresso no serviço público, com resDe umento das vantagens ligadas ao cargo. Mas resulta de que ? te. uma demissão considerada injusta pela autoridade competenC De modo que só há falar em reintegração de quem já foi mitidante efetivo de cargo público e que dele foi injustamente decorro. E decorre de decisão judicial embora possa também denistrer de decisão administrativa. Nesta hipótese, a decisão admiem trativa que determinar a reintegração será sempre proferida pedido de reconsideração, em recurso ou em revisão de proesso de que se originou a demissão. 
3 - O mesmo autor aduz a seguir: "Readmissão é a opera. ção pela qual o ex-funcionário, demitido ou exonerado, reingres. sa no serviço público, sem direito a ressarcimento de prejuízos (ao contrário do que acontece com a reintegração), assegurada tão-só a contagem de tempo de serviço em cargos anteriores para efeito de aposentadoria e disponibilidade. A readmissão dar. se-á depois que a Administração, reexaminando o processo administrativo de que resultou a demissão, entender demonstrado não ser inconveniente para o serviço público".

Demissão nunca poderia ensejar readmissão e sim reinte. gração, assim mesmo se fosse ela, a demissão considerada injusta através de processo regular.

\section{Mas, readmissão não existe mais !}

O Decreto-lei n. ${ }^{\circ} 200$, de 25 de fevereiro de 1967, em seu artigo 113, revogou expressamente o instituto da readmissão. Eis 0 texto legal: "Revogam-se, na data da publicação da presente lei, os artigos 62 e 63 da Lei n. 1.711, de 28 de outubro de 1952, e demais disposições legais e regulamentares que regulam as readmissões no Serviço Público Federal".

Referido livro não consigna a data de sua edição, mas tudo nos leva a crer seja de 1971, pelo menos faz referência à Emenda Constitucional de 1969 e ao Decreto-lei n. 200, de 1967, bem co. mo ao Decreto-lei $n .^{\circ} 900$, de 1969 , que lhe alterou certos dispositivos. Não podia, assim, ignorar o que dispôs o artigo 113 daquele diploma legal.

4 - Nem sempre o legislador é feliz ao expressar seu pensamento, e daí resultam impropriedades no linguajar dos menos avisados, inclusive de autores de livros de Direito Administrativo. Vejamos, primeiro, o que diz aquele autor: "Os princípios gerais que regem o funcionalismo público da Nação são os da Constitulção da República Federativa do Brasil, de 1969, a saber : a) — to dos os cargos são criados em lei, e preenchidos na primeira inves. tidura mediante concurso público de provas ou provas e títulos; b) - os cargos públicos são acessíveis a todos os brasileiros que preencham os requisitos estabelecidos em lei; c) - é proibida a acumulação remunerada de cargos e funções públicas, exceto: I) a de juiz com um cargo de professor; II) - a de dois cargos de professor; III) - a de um cargo de professor com outro técnico ou científico; IV - a de dois cargos privativos de médico. Além disso somente é permitia a acumulação quando houver correlação de matérias e compatibilidade de horários. A proibição de acumu 
lar é extensível às autarquias, empresas públicas e sociedades de economia mista".

Realmente, os princípios gerais que regem a vida funcional emanam da Constituição Federal, embora decorram também do Estatuto dos Funcionários. O princípio que diz que os cargos são Criados por Lei é estatutário e não constitucional. A antiga Lei de Classificação de Cargos ( . $^{\circ} 3.780$, de 1960) retomou o princípio dos Estatutos de 1939 e de 1952, dizendo que cargo é o conjunto de atribuições e responsabilidades cometidas a um funcionário, mantidas as características de criação por lei etc.

O restante da letra a resulta de transcrição abreviada do preceito contido no $\S 1 .^{\circ}$ do artigo 97 da Emenda n..$^{\circ}$, de 1969, e que nos poderia levar a uma interpretação absurda: somente na primeira investidura é que os cargos públicos seriam providos por meio de concurso público. Já se vê que a palavra primeira constante do mandamento constitucional é demais ou deverá ser entendida em termos, no sentido de que cada investidura deverá ser antecedida de aprovação em concurso público: cada investidura em cargo público é uma primeira investidura, não importe se o funcionário já seja detentor de outro cargo.

A letra c é reprodução do texto constitucional : "É vedada a acumulação remunerada de cargos e funções públicas, exceto: I - a de juiz com um cargo de professor". Flagrante impropriedade! Não é juiz que acumula com professor e sim o cargo de juiz que é acumulável com o cargo de professor. Aliás, o Professor Mário Masagão cambém observou essa impropriedade em seu Curso de Direito Administrativo (Editora Revista dos Tribunais, 4." edição, 1968, p. 225), aduzindo que "juiz não é coisa que se Possa acumular".

Por outro lado, não é a proibição de acumular que é extensíVel às autarquias, empresas públicas e sociedades de economia mista e, sim, o regime de acumulação remunerada de cargos e funções públicas é que se aplica, pois que nesse regime, como é óbvio, se inclui tanto a regra geral de proibição quanto as exceções... Demais disso, seria mais próprio dizer que se estende aos servidores das autarquias, empresas públicas e sociedades de economia mista, pois que são eles que acumulam cargos e funcões públicas e não os órgãos.

5 - Certa feita, por havermos criticado, em sentido doutrinário, a redação do preceito constitucional referente à acumulação de cargos que voltou a ser acumulação remunerada na Consti- 
tuição de 1967, determinado jurista, a título de defender menos a redação que o seu autor, ou talvez mais para verberar o que tivera a coragem de mostrar o cochilo do redator da nova norma, aduziu que, em tempos idos, já fizera um trabalho sobre o assunto. Se assim é, ninguém mais deveria escrever sobre Direito de Família no Brasil porque Lafayete Pereira e Clóvis Bevilaqua já escreveram livros sobre esse capítulo do Direito Civil. Aliás, ninguém escreveria mais sobre coisa alguma, pois que quase to. dos os temas já foram explorados por autores os mais diversos e sob ângulos diferentes. Qualquer estudioso sabe que se pretender pesquisar determinado assunto, a bibliografia que irá encontrar é enorme e, não raro, quase impossível de ser toda ela co. nhecida. Quase sempre o que ainda pode acontecer é a desco. berta de um documento não revelado até então ou a interpretação sistemática dos documentos já conhecidos.

Sobre o assunto acumulação de cargos, a mim não me aba. la saber que faz algum tempo um contemporâneo publicou uma compilação a partir de 1623, data da Carta Régia referida em alguns índices Cronológicos e num decreto da República referente ao assunto (Decreto n. 7.503 , de 12 de agosto de 1909). Pesquisar é ir além disso, é aprofundar na busca de documentos acaso existentes. E foi o que fiz, procurando tecer a história do instituto das acumulações não só com o que já era por muitos conhecido como com documentos inéditos.

Demais disso, consegui localizar as raízes de nosso orde. namento jurídico relativo ao assunto, não no século XVII (1623) mas no século XV, na administração diárquica dos Reis Católicos (Fernando V e Isabel de Castela), isto é, nas Ordenanzas dadas en Medina (Veja-se "Primeiros Documentos referentes ao acúmulo de cargos públicos (dos "Reis Católicos" a D. João VI)" in Ad. ministração e Legislação - Ministério da Educação e Cultura Ano I - n. ${ }^{\circ} 1$ - setembro de 1971).

Desgastadas já estão as citações do pobre do Padre Vieira e do versículo bíblico do Evangelho Segundo São Mateus de que ninguém pode servir bem a dois senhores etc., pois que a essên. cia do regime de proibição de acumular cargos e funções emana senão do princípio da divisão do trabalho e da especialização $c 0$ mo da própria natureza das coisas.

Como quase tudo há de ter suas origens na civilização grega, não nos será difícil verificar que Péricles, no século V antes de Cristo, já adotava a política de proibição de os funcionários, os arcontes, acumularem duas magistraturas. Isso é fácil de ver per- 
lustrando a obra do sábio suiço André Bonard - Civilisation Greque de I'lliade au Parthénon.

6 - o artigo 195, item XI, da Lei $n .{ }^{\circ} 1.711$, de 8 de outubro de 1952 (Estatuto dos Funcionários) diz textualmente: "Art. 195. Ao funcionário é proibido: (..) XI. Cometer a pessoa estranha à repartição, fora dos casos previstos em lei, o desempenho de encargo que lhe competir ou a seus subordinados". A matéria desse mandamento estatutário remonta a dois Alvarás Régios de D. Filipe III de Portugal e IV de Espanha. São os Alvarás Régios de 23 de novembro de 1612 e 9 de setembro de 1647, que exigiram a obrigatoriedade de o funcionário "servir por si o seu ofício".

Aquele preceito contém igualmente o princípio de Direito Administrativo de que nenhum funcionário pode deferir a outro matéria de sua competência legal.

7 - O parágrafo único do artigo 24 do Estatuto dos Funcionários diz: "o funcionário declarará, para que figurem obrigatoria. mente no termo de posse, os bens e valores que constituem seu patrimonio". Medida salutar que remonta, igualmente, ao século XVII. A Lei de 31 de janeiro de 1629 obrigou "a todos os Ministros - Oficiais da Fazenda, que servissem desde 1592, a fazerem inventário de seus bens debaixo de juramento, entregando-o antes de se Ihes darem as suas Provisões", o mesmo acontecendo com a Carta Régia de 5 de abril de 1624, em que Filipe III determinou Se não pagasse ordenado ao Ministro que não apresentasse inventário de seus bens, norma que foi reiterada no Decreto de 19 de Outubro de 1654.

8 - Em termos de pesquisa, é oportuno registrar a que fizemos nos idos de 1960, no Arquivo Nacional. Pretendendo o Governo oferecer aos funcionários públicos um atrativo para se mudarem para a nova Capital da República, idealizou-se o pagamento de diárias que logo passou a se chamar diárias de Brasília e, um pouco mais tarde, dobradinha pois que consistia, em última análise, em verdadeiro pagamento em dobro do vencimento. Em 1961, haVia certos altos funcionários que tinham dúvida sobre a legalidade daquele pagamento, havendo mesmo, ao que se afirmava, um $\mathrm{Mi}$ nistro do Tribunal de Contas que se recusara, por algum tempo, a receber aquela vantagem.

Pois bem, em julho de 1961, divulguei o resultado de uma Pesquisa que fiz, dizendo a um jornal carioca que a diária que se concedia a funcionários designados para servir em Brasília, e que se popularizou pelo nome de dobradinha, não constituia nenhuma novidade, pois que era uma velharia de três séculos. 
Com efeito, o Alvará Régio baixado por D. Pedro II, Rei de Portugal, em 19 de dezembro de 1699, instituiu o salário em dobro, em virtude de ser, ordinariamente, mais cara a vida no Brasil. Poucos os funcionários categorizados do Reino que queriam vir servir no então chamado Estado do Brasil, e o Alvará Régio objetivou seduzir, nesse sentido, aqueles funcionários e, ao mesmo tempo, atribuir um auxílio governamental ao servidor público obrigado a novo padrão de vida.

Esclareça-se que D. Pedro II, de Portugal, foi um administrador enérgico, e, em certo sentido, mais severo que o próprio Marquês de Pombal. Pois D. Pedro II, que colocou em verdadeira "roda viva" os acumuladores de cargos, concedeu salário em dobro, aos que viessem servir às repartições sediadas no Brasil, sem deles exigir, entanto, tempo integral e dedicação exclusiva.

Dizia textualmente o Alvará Régio: “Em consideração do excesso do preço, em que todas as coisas se acham de presente, ao tempo em que a Ordenação se fez, e que no Estado do Brasil tudo é mais caro ordinariamente do que neste Reino, hei por bem que todos os Oficiais de Justiça do Estado do Brasil possam levar os salários em dobro do que está taxado pela Ordenação, a qual se guardará em tudo o mais".

Acrescente-se que, no princípio do Século XVIII, o Regimen. to do Auditório Eclesiástico do Arcebispado da Bahia, e do Conselho do Rei, adotava o mesmo preceito contido naquele Alvará Régio de 1699.

Há que considerar que Ofical era o nome que se dava, na época, a quem servisse um ofício ou emprego público. Oficiais do Juízo ou de Justiça era a designação genérica que se atribuía aos que serviam à administração da Justiça, assim à secular quanto à eclesiástica, tais como Ministros, Desembargadores, Juízes Sin. gulares, Vigários-Gerais, Procuradores, Promotores, Provisores, Advogados, Solicitadores, Notários, Tabeliães, Escrivães, Contado. res, Distribuidores, Meirinhos, Depositários, Porteiros da Relaçãa e dos Auditórios etc. Hoje é que Oficial de Justiça é somente 0 antigo Meirinho ou Oficial de Diligência.

De modo que era a grande maioria senão quase à totalida. de dos servidores públicos que se aplicava o mandamento régio de salário dobrado, pelo desempenho de ofícios ou empregos pút blicos nesta "província d'além mar", ainda terra de degredados.

9 - Variações de paz sobre um tema de Guerra. Gostaria de escrever algumas considerações sob este título, mas a mim me 
falta, talvez, ânimo para enfrentar o assunto. Provavelmente isto acontece porque não tenho bem certeza se o Professor José AuGusto Guerra está inteiramente sem razão ao tecer severas crítiCas à redação oficial, aquela que diariamente usamos, nós outros, pobres escribas da Administração, na monografia intitulada - A Técnica da Comunicação na Redação Oficial - com que logrou Ser premiado no Concurso de Monografias da Revista do Serviço Público de 1970 e ora publicada no Volume 108, n. ${ }^{\circ} 3$ (set./dez. 1973), da mesma Revista. É um trabalho inegavelmente bem escrito e o que diz o autor tem lá sua procedência. Ao emitir mitha opinião sobre essa monografia, como integrante que fui da Comissão Julgadora, tive oportunidade de afirmar tratar-se de uma monografia cativante pela crítica bem humorada que faz à linguagem emperrada e falsamente cerimoniosa usada na correspondência oficial, pugnando, seu autor, "em favor de uma linguagem oficial despida de atavios e circunlóquios que se manifestam nas fórmulas ditas de cortesia, na adjetivação supérflua, nas perífrases redundantes, nas metáforas, nos preciosismos, nos lugares comuns. Enfim: em tudo o que torna o pensamento opaco e dificulta a informação, a interpretação e a opinião de quem redige".

Conclui o Professor Guerra por sugerir ao DASP que inicie "amplos estudos sobre a matéria", a fim de oferecer "ao redator possibilidades de criação, de renovação constante, sem quebra, evidente, das distinções específicas que caracterizam um ofício, uma ata, um memorando, uma exposição de motivos".

Em princípio, entendo ser válida a tese, embora se possa ponderar que o estilo, mesmo em correspondência oficial, mesmo em pareceres, depende muito da formação intelectual e do gosto de cada qual, bem como do conhecimento que cada qual possui do assunto que deva levar para o papel. Ninguém desconhece que, em geral, só redige claro quem sabe claro o assunto, quem sabe Pensar claro. Para tanto, o coeficiente pessoal é ponderável.

Se a Administração Pública, como pretende o Professor Guerra, libertar o funcionário de um mínimo de formalismo na redação oficial, correrá o risco do ridículo, porque nem todos possuem o senso da medida e da conveniência. Nem todos possuem o sentido da medida do termo exato e adequado para usá-lo no momento certo e conveniente. Nem todos estariam preparados para se sobreporem aos clichês e às expressões de rotina dentro de certo desenho fraseológico. Daquelas expressões de rotina que adequam o assunto e empurram o pensamento. E seria inevitável que ao se libertar de uma rotina se enveredasse em outra, porque o estilo, é até certo ponto, uma rotina, e não vai mal que 
a Administração, que tem sua personalidade, tenha também o seu estilo, vale dizer, a sua rotina. E a rotina é salvadora, não raro, porque condiciona o escriba do Serviço Público e o orienta na construção do texto que deverá redigir e, conseqüentemente, no disciplinamento do que deve ver, do que deve colher, do que deve expressar, das premissas que deve compor para, afinal, chegar a uma conclusão lógica, racional fundamentada. A clareza no dizer tem também seus andaimes, como o tem qualquer gênero literá. rio. O corpo humano, por mais ágil e dextro que seja - de um bailarino ou de um acrobata - , tem sempre implícito o seu es. queleto. O esqueleto é universal, permanente, indispensável, em. bora nem sempre suspeitado.

Se o funcionário possui a técnica de se comunicar, se do. mina os fatos da linguagem, se se adestrou no manejo do idioma, mesmo dentro desse regime de linguagem, oficial, tão criticado (até certo ponto, com razão, pelo Professor Guerra), saberá escre. ver bem, saberá comunicar-se bem, como acontecia com Machado do de Assis, no parecer que emitiu sobre um dispositivo da Lei do Ventre Livre e a que o Professor faz referência. Ainda no século XIX, portanto, havia funcionário, como o velho Machado de Assis, que sabia ter estilo próprio, liberto do incômodo espartilho das fórmulas estereotipadas já naquela época passíveis de crítica. A esse fato, atribui o Professor Guerra (que é também bacharel em Direito) a circunstância de não ser Machado bacharel, pois que sua linguagem "difere inclusive do estilo bacharelesco", sendo "precisa e enxuta". Ora, é preciso atentar que a linguagem dita bacharelesca nem sempre se há de debitar ao bacharel e, sim, aos que não sabem emitir um pensamento numa linguagem desatavia. da, objetiva, simples e direta, bacharéis ou não. Machado de As. sisti escrevia bem não porque não era bacharel e, sim, porque era um escritor, isto é, era um artista da palavra escrita.

O Professor Guerra traz como exemplo de boa linguagem Filipe I de Portugal e II de Espanha, que era do Século XVI, e Pero Vaz de Caminha. Donde se conclui que escrever bem é uma ques. tão de gosto pessoal, pois que dessa mesma época há textos in sôssos, inexpressivos, confusos e que pouco ou nada transmitem.

Coelho Neto, citado pelo Professor Guerra é fruto de uma mentalidade que coexistiu com outra que nos deu Euclides da Cunha ou Humberto de Campos. Coelho Neto, na expressão da. quele poeta peranambucano, macaqueava a sintaxe lusa. Quando ainda muito jovem, na província, conheci um jovem escritor que, por sua vez, macaqueava o estilo de Coelho Neto, e, ainda hoje, guarda o mesmo estilo... 
De modo que a questão é pessoal : a redação oficial será boa se o tuncionário dominar o idioma, conhecer o assunto e... ter algum estilo. E estilo é conhecimento do assunto. Ninguém tem estilo se não conhece bem o que vai escrever, assim como ninguém é poeta se não tem inspiração.

De mais a mais é bom que se reconheça que o estilo da redação oficial melhorou consideravelmente, sobrevivendo, embora, alguns pedantismos de um que outro auto-suficiente que redigem, eles próprios, seus pareceres e os assinam, assumindo a responsabilidade de seus aleijões. É pena que o Professor Guerra não se deu ao trabalho de distinguir para não ser injusto. Fez um trabatho caricatural, esquecido dos bons exemplos de boa linguagem existente no seio do funcionalismo, e que a pletora de trabalho não dá vagares ao funcionário para burilar os expedientes a ponto de fazer de cada despacho ou parecer uma obra-prima de valor literário. Mas, a despeito de quanto dissemos, estas variações ainda são de paz, como pretendíamos de início, pois não é pequena nossa simpatia pelo Professor José Augusto Guerra. 
